\title{
Variations and results of retroauricular robotic thyroid surgery associated or not with neck dissection
}

\author{
Renan Bezerra Lira, Thiago Celestino Chulam, Luiz Paulo Kowalski \\ Department of Head and Neck Surgery and Otorhinolaryngology, A.C. Camargo Cancer Center, Sao Paulo, Brazil \\ Contributions: (I) Conception and design: All authors; (II) Administrative support: All authors; (III) Provision of study materials or patients: All \\ authors; (IV) Collection and assembly of data: RB Lira; (V) Data analysis and interpretation: RB Lira; (VI) Manuscript writing: All authors; (VII) \\ Final approval of manuscript: All authors. \\ Correspondence to: Renan Bezerra Lira, MD, PhD. Department of Head and Neck Surgery and Otorhinolaryngology, A.C. Camargo Cancer Center, \\ Rua Prof. Antonio Prudente, 211, Sao Paulo 01509-900, Brazil. Email: renan.lira@accamargo.org.br.
}

Background: Technological advances in the last decades allowed significant evolution in head and neck surgery toward less invasive procedures, with better esthetic and functional outcomes, without compromising oncologic soundness. Although robotic thyroid surgery has been performed for some years now and several published series reported its safety and feasibility, it remains the center of significant controversy. This study shows the results of a case series of robotic thyroid surgery, combined or not with robotic neck dissection.

Methods: A retrospective cohort including 48 cases of robotic thyroid surgery with or without neck dissection, using retroauricular or combined approaches, performed in a tertiary cancer center, comprised the study.

Results: Between 2015 and 2017, we performed 2,769 thyroid surgical procedures, of which 48 (1.7\%) were robot-assisted, in 46 patients [ 26 hemithyroidectomies, 7 total thyroidectomies, and 12 total thyroidectomies (or totalization) with selective neck dissection (SND) II-VI; and 3 neck dissections for thyroid carcinoma]. There were $43(89.6 \%)$ women, and the median age was 35 years. The mean hospital stay was 1.9 days. In $3(6.2 \%)$ cases, drains were not placed (hemithyroidectomies), whereas the other $45(93.8 \%)$ cases had a mean drain stay of 4.4 days (range, 1-9 days). The console time (robotic thyroid resection and neck dissection) ranged from 11 to $200 \mathrm{~min}$ (mean $66.1 \mathrm{~min}$; median $40 \mathrm{~min}$ ), and the total operating room time ranged from 80 to $440 \mathrm{~min}$ (mean $227.9 \mathrm{~min}$; median $170 \mathrm{~min}$ ). Three (6.2\%) patients had transient vocal cord paresis. Transient hypocalcemia was reported in three cases $(6.2 \%)$. There were 30 carcinomas (62.5\%), and the mean number of retrieved lymph nodes (LNs) (considering only cases that included robotic neck dissection) was 27.2 (range, 17-40). The mean follow-up time was 17.4 months (range, 1.4-31.9 months), and no recurrence was diagnosed.

Conclusions: The quality outcomes and complication rates are comparable to the conventional approaches. Therefore, robotic thyroidectomy can be an option for selected patients that are motivated to avoid a visible neck scar, treated in high-volume centers. For the patients who require lateral neck dissection, the retroauricular robotic approach could be even more attractive, especially for young patients.

Keywords: Thyroid surgery; thyroidectomy; robotic surgery

Submitted Feb 19, 2018. Accepted for publication Feb 28, 2018.

doi: 10.21037 /gs.2018.03.04

View this article at: http://dx.doi.org/10.21037/gs.2018.03.04 


\section{Introduction}

There are secular patient wishes and professional concerns in reducing functional and cosmetic morbidity without compromising oncological outcomes in cancer treatment. In recent decades, oncologic surgery has been making remarkable progress with the development of minimally invasive surgical procedures, leading to significant improvements in satisfaction and quality of life of treated patients (1). Several technological developments such as the use of advanced energy devices have allowed the development of alternative minimally invasive approaches in head and neck surgery (2). Among these advances, endoscopic and robotic procedures have been incorporated by many centers around the world. In selected cases, these surgical technologies eliminate the need for large visible neck incisions and provide superior functional and cosmetic results, with an acceptable cost and low complication rates that are equal or lower than those of classical procedures (3-10). In 2005, McLeod and Melder performed the first robotic procedure on head and neck with the resection of a vallecular cyst (11). O'Malley et al. have reported that the improved visualization allowed them to obtain better resections with adequate oncological margins, excellent hemostasis, and facilitated the conservation of important neural structures in resections of tumors of the tongue via transoral robotic surgery (TORS) (12). Subsequently, the treatment of eligible cases of oropharyngeal tumors via TORS had progressive development and propagation (13-15).

In addition to TORS, the use of the da Vinci ${ }^{\circledR}$ Robotic Surgical System (Intuitive Surgical, Sunnyvale, CA, USA) has allowed the development of several other less morbid surgical approaches, including the transaxillary and retroauricular approaches for thyroidectomies, neck dissections, and salivary gland resections (parotid and submandibular). These alternative approaches initially gained space in Asia, especially in South Korea and China, and most of the experience and publications to date come from these countries. DJ Terris, simultaneously with Korean authors such as Koh and Choi, was one of the pioneers in robotic thyroidectomy via facelift or retroauricular approach, performing the first cases in the US in 2011 with a series of 14 patients. It is important to emphasize that Terris in his series excluded all patients with LN disease (16). Some centers from Asia have extended the indications and showed the safety and feasibility of combining robotic thyroid surgery with robotic neck dissection with promising results (17-20).

In recent years, other American centers and some centers in other countries started to use robotic surgery for neck procedures, including thyroidectomy, especially via retroauricular incision $(3,7,21-23)$. The objective of this study is to report the initial experience of a tertiary center of oncology in robotic thyroidectomy, combined or not with neck dissection, performed by the retroauricular approach.

\section{Methods}

\section{Study design}

A retrospective cohort study was designed. The cohort consisted of all patients submitted to any modality of retroauricular approach and robot-assisted surgical treatment for thyroid disease from March 2015 to September 2017 at the Department of Head and Neck Surgery and Otorhinolaryngology of the A.C. Camargo Cancer Center and four cases that received surgical treatment at Sirio Libanes Hospital, São Paulo, Brazil. The surgical procedures included: (I) hemithyroidectomy via the unilateral retroauricular approach; (II) total thyroidectomy via the unilateral retroauricular approach; (III) total thyroidectomy via the bilateral retroauricular approach; (IV) total thyroidectomy with selective neck dissection (SND) II-VI via the unilateral retroauricular approach; (V) total thyroidectomy with SND II-VI via the bilateral retroauricular approach; (VI) total thyroidectomy with SND II-VI via the unilateral retroauricular approach combined with the mini-Kocher approach.

We propounded robot-assisted hemithyroidectomy via the unilateral retroauricular approach for patients with unilateral thyroid disease that included symptomatic nodular goiter, undetermined follicular neoplasms, and papillary thyroid microcarcinomas. Total thyroidectomy had similar indications, but for bilateral thyroid disease. Robot-assisted thyroidectomy combined with neck dissection was offered to patients with papillary thyroid carcinoma with confirmed lateral neck metastasis but with no signs of invasion of any non-lymphatic structures (T1-3N1bM0). These cases with lateral neck metastasis also received central compartment neck dissection. All patients who underwent these procedures made the decision for the approach themselves after being fully informed about the advantages and disadvantages of the treatment options, including possible conversion to a conventional transcervical approach. 


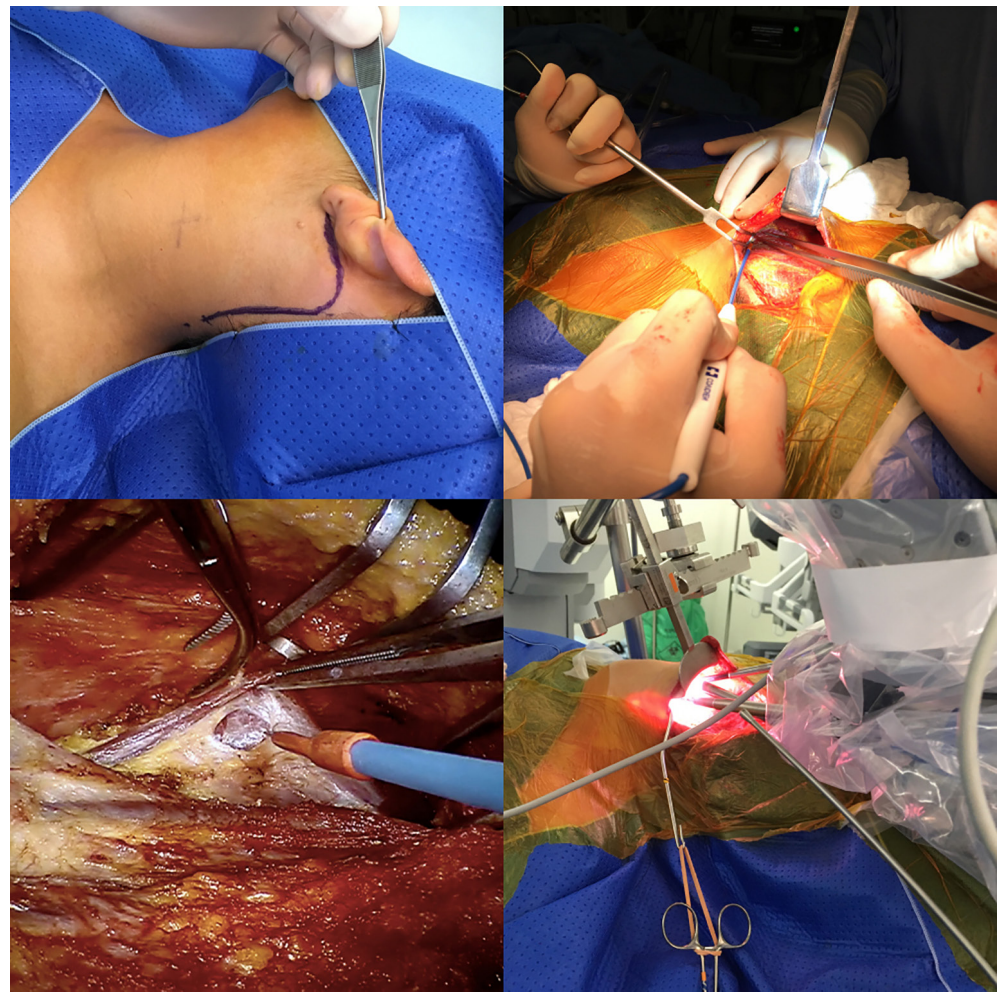

Figure 1 Left retroauricular approach for robotic hemithyroidectomy: incision planning, skin flap dissection, thyroid lobe exposure and robotic system docked.

\section{Surgical technique}

For both the robot-assisted thyroidectomy and SND, a retroauricular approach was performed as previously described by the Yonsei University in Seoul and subsequently reproduced at our department for different neck surgical procedures (21-24). In summary, after positioning the patient, a skin incision was made behind the auricle from the lower end of the retroauricular sulcus upward to the midpoint of the sulcus, and then smoothly angulated downward approximately $0.5 \mathrm{~cm}$ inside the hairline (Figure 1). Subsequently, a subplatysmal skin flap was raised above the sternocleidomastoid muscle (SCM) proceeding anteriorly to the midline of the neck. In cases of neck dissection, it can be extended superiorly to the submandibular gland and inferiorly to the level of the clavicle and sternal notch. For thyroid exposure, the anterior inferior border of SCM is dissected, and the infrahyoid muscles are separated from the ipsilateral thyroid lobe and sustained by a Bookwalter ${ }^{\circledR}$ (Symmetry Surgical Inc., Antioch, TN, USA) self-retaining retractor establishing an adequate working space for the thyroid surgery
(Figure 1). Next, the da Vinci Surgical System is docked with three arms (one camera arm with a 30-degree dual channel endoscope and two instrument arms equipped with a 5-mm Maryland dissector forceps and 8-mm Harmonic $\mathrm{ACE}^{\circledR}$ curved shears (Johnson and Johnnson Medical, Cincinnati, OH, USA). The thyroid dissection is then performed with proper visualization of the parathyroids and laryngeal nerves (including dissection of level VI when necessary) (Figure 2).

For SND II-V, prior to docking the robotic system, dissection of the accessory nerve and levels II-III was accomplished under direct vision without magnification using a surgical headlight and regular surgical instruments. After docking the da Vinci system with the same instruments, dissection of levels IV-V was performed robotically assisted, according to the technique previously described by Yonsei University. At the end of the procedure, careful hemostasis was obtained, and a Blake ${ }^{\circledR}$ (Johnson and Johnnson Medical, Cincinnati, OH, USA) drain with bulb suction was placed in almost every patient (except in three hemithyroidectomies). Postoperative drainage was 


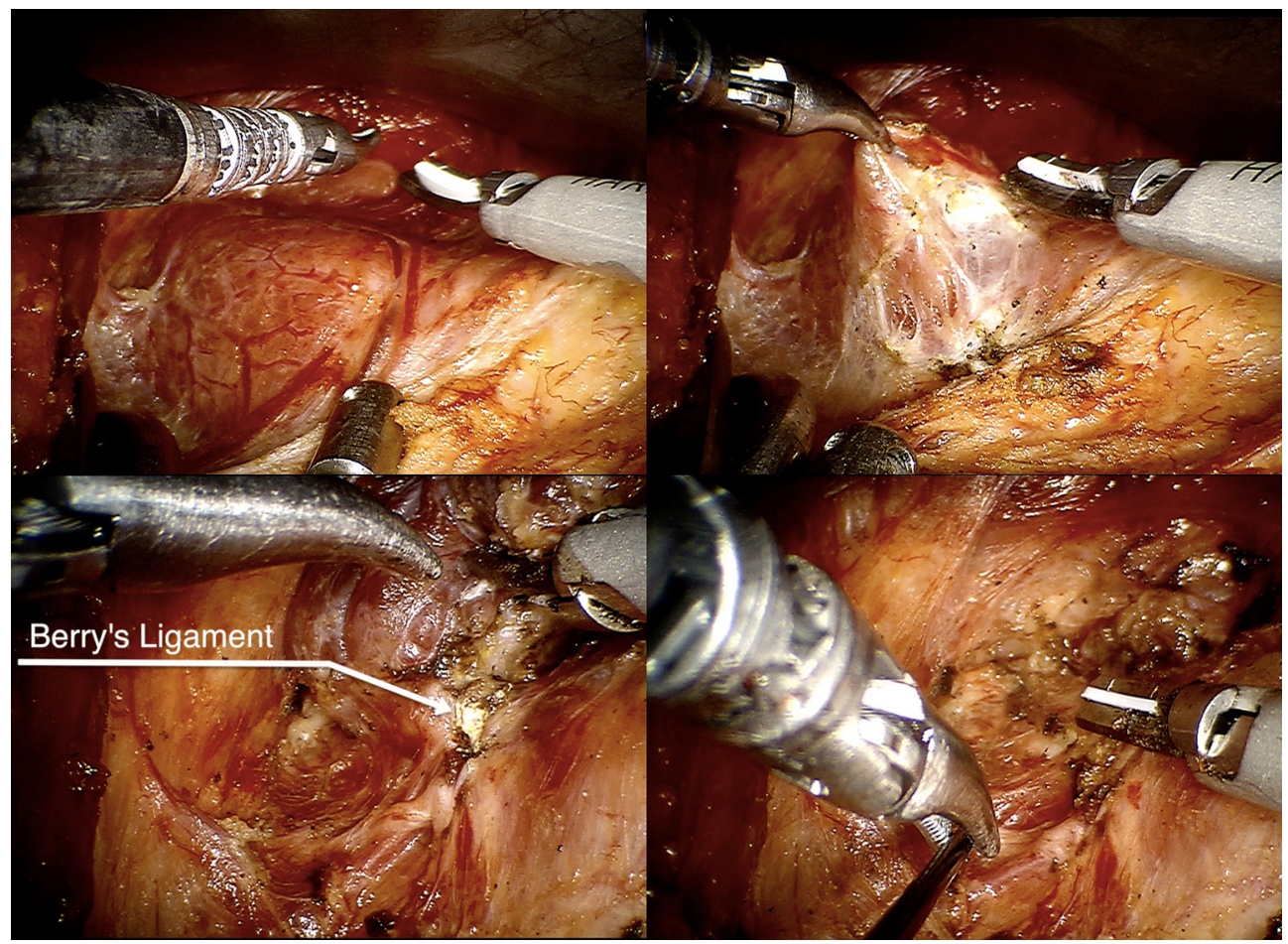

Figure 2 Robotic left hemithyroidectomy (retroauricular approach): thyroid lobe exposed, upper pole dissection, Berry's ligament dissection and nerve monitoring at the end of the procedure.

measured every 24 hours, and the drain was removed when the flow was less than $20 \mathrm{~mL} / 24$ hours (usually on the 5 th postoperative day). After discharge, all patients were followed up in the outpatient setting and were submitted to postoperative laryngoscopy to assess vocal cord mobility.

\section{Data analysis}

Electronic medical charts were reviewed. Demographic data were retrieved including age, gender, and body mass index (BMI; $\mathrm{kg} / \mathrm{m}^{2}$ ). Clinicopathological characteristics recorded included histopathological diagnosis of the primary tumor, clinical and pathological staging according to the TNM classification, and side and extent of the SND. To assess the primary endpoint of this study, defined as the feasibility of the retroauricular approach, perioperative and postoperative treatment outcomes of the patients up to the first postoperative month were evaluated and compared, including outcome quality indicators (25) and perioperative local and systemic complications (e.g., seroma, hematoma, surgical site infection, chyle leakage, cranial nerve impairment, and skin flap dehiscence or necrosis). The results were compared with MD Anderson Cancer Center's previously published benchmarks for quality assessment in low acuity head and neck procedures (25-27). To assess an early oncologic outcome, total number of LNs retrieved and recurrence rate were evaluated. A descriptive analysis of the data was performed.

The study received ethics approval by the local institutional review board (project number 1913/14). Informed consent was obtained from all patients for being included in the study.

\section{Results}

Between 2015 and 2017, we performed total of 2,769 thyroid surgical procedures at the department of Head and Neck Surgery and Otorhinolaryngology of the AC Camargo Cancer Center, of which 44 (1.6\%) were robot-assisted, including hemithyroidectomies, total thyroidectomies, and thyroidectomies combined with neck dissection. Three patients (four procedures) were operated on at Sirio Libanes Hospital. These 48 robot-assisted surgical procedures were included in this study, performed in 46 patients ( 2 patients were submitted to hemithyroidectomy followed by totalization, 1 combined with neck dissection): 
26 hemithyroidectomies; 7 total thyroidectomies; 12 total thyroidectomies (or totalization) with SND II-VI; and 3 neck dissections for thyroid carcinoma (Table 1). We have 10 head and neck surgeons in our department, of which three have technical training for robotic neck surgery. These three surgeons performed all included cases as follows: surgeon A, 37 cases; surgeon B, 6 cases; and surgeon C, 5 cases.

In this group, we had $43(89.6 \%)$ procedures performed in women and $5(10.4 \%)$ in men. The median patient age was 35 years (mean 37.6; range, 20-69 years). The BMI of these patients ranged from 16 to 39 (mean 25 , median 24).

Of the 48 procedures, in 37 (77\%) cases the hospital stay was 2 days or less, and only $3(6.2 \%)$ patients spent more than 3 days in the hospital. The mean hospital stay was 1.9 days. In $3(6.2 \%)$ cases drains were not placed (hemithyroidectomies), whereas the other 45 (93.8\%) patients had a mean drain stay of 4.4 days (median 4; range, 1-9 days). The console time (robotic thyroid resection and neck dissection) ranged from 11 to 200 min (mean 66.1 , median $40 \mathrm{~min}$ ), and the total operating room time ranged from 80 to $440 \mathrm{~min}$ (mean 227.9, median $170 \mathrm{~min}$ ). There was no readmissions or mortality due to surgical complications. One (2\%) patient required reoperation for a lymphatic fistula, and one (2\%) other patient had surgical site infection treated with oral antibiotics. We had no hematomas. All but three (6.2\%) patients presented with normal vocal cord mobility during the laryngoscopy performed at the first postoperative outpatient evaluation. In these three patients, level VI was robotically dissected, and one of them had laryngeal nerve shaving. All three vocal cords had full recovery in up to 3 months. Transient facial marginal branch paresis occurred in four $(8.3 \%)$ patients, but all cases were normalized in a month. Transient hypocalcemia was reported in three $(6.2 \%)$ cases. No other surgical complications were described. We compared these outcome indicators with MD Anderson Cancer Center's previously published benchmarks for quality assessment in low acuity head and neck procedures (Table 2) (25-27).

The final pathology reports showed benign disease in 18 (37.5\%) patients (4 follicular adenomas, 4 follicular hyperplasias, and 10 colloid nodules) and $30(62.5 \%)$ carcinomas, of which 29 were papillary carcinomas and 1 was a 2 -cm Hurthle cell carcinoma. During hemithyroidectomy for one of the patients with papillary microcarcinoma, a suspect level III LN was removed and although frozen section has failed to show metastatic disease, the final pathology report diagnosed a pT1aN1bM0 papillary carcinoma, and the patient was scheduled for combined approach (mini-Kocher and robotic retroauricular) thyroid totalization and ipsilateral central and lateral neck dissection of levels II-VI. The patient with the Hurthle cell carcinoma was initially submitted to robotic hemithyroidectomy for Bethesda IV thyroid nodule. However, after multidisciplinary discussion of her final diagnosis, totalization via contralateral robotic retroauricular approach was performed. The mean number of retrieved LNs (considering only cases that included robotic neck dissection) was 27.2 (range, 17-40).

The mean follow-up time was 17.4 months (range, 1.4-31.9 months), and no recurrence was diagnosed.

Aesthetic outcomes were considered superior when subjectively compared to conventional approaches in our experience (Figure 3).

\section{Discussion}

Several different remote approaches for thyroid surgery were described and studied in the last decades (28-30). The main objective has been to develop alternative approaches to achieve better aesthetic outcome avoiding a visible neck scar. However, the negative impact of a 4 to $6 \mathrm{~cm}$ scar from a Kocher incision, which is used for thyroid surgery and central neck compartment neck dissection, varies among patients, and the value of aesthetic outcome in this scenario is also very individual. In the patients who receive surgery with extracervical approaches, the aesthetic satisfaction seems to be superior, according to a systematic review published in 2014 comparing robotic to conventional thyroidectomy (8), as well as other publications $(31,32)$; however, in our opinion, only patients motivated to avoid a visible neck scar and worried about this should be encouraged to remote approaches using robotic or endoscopic thyroidectomy.

Most of the experience with remote approaches to the thyroid come from Asia, especially South Korea $(8,33)$, and most of the data published on robotic thyroid surgery explore the gasless transaxillary approach. The retroauricular or facelift approaches have gained attention more recently and, consequently, we find fewer publications analyzing it $(3,6,7,16,21,22,34-43)$. Although composed mostly of initial series of cases, this growing body of evidence supports the safety and efficacy of the approach and shows that it has been performed for selected patients at several centers around the world, including some centers in US (7). Some systematic reviews and meta-analyses 
Table 1 Demographic data and operative details

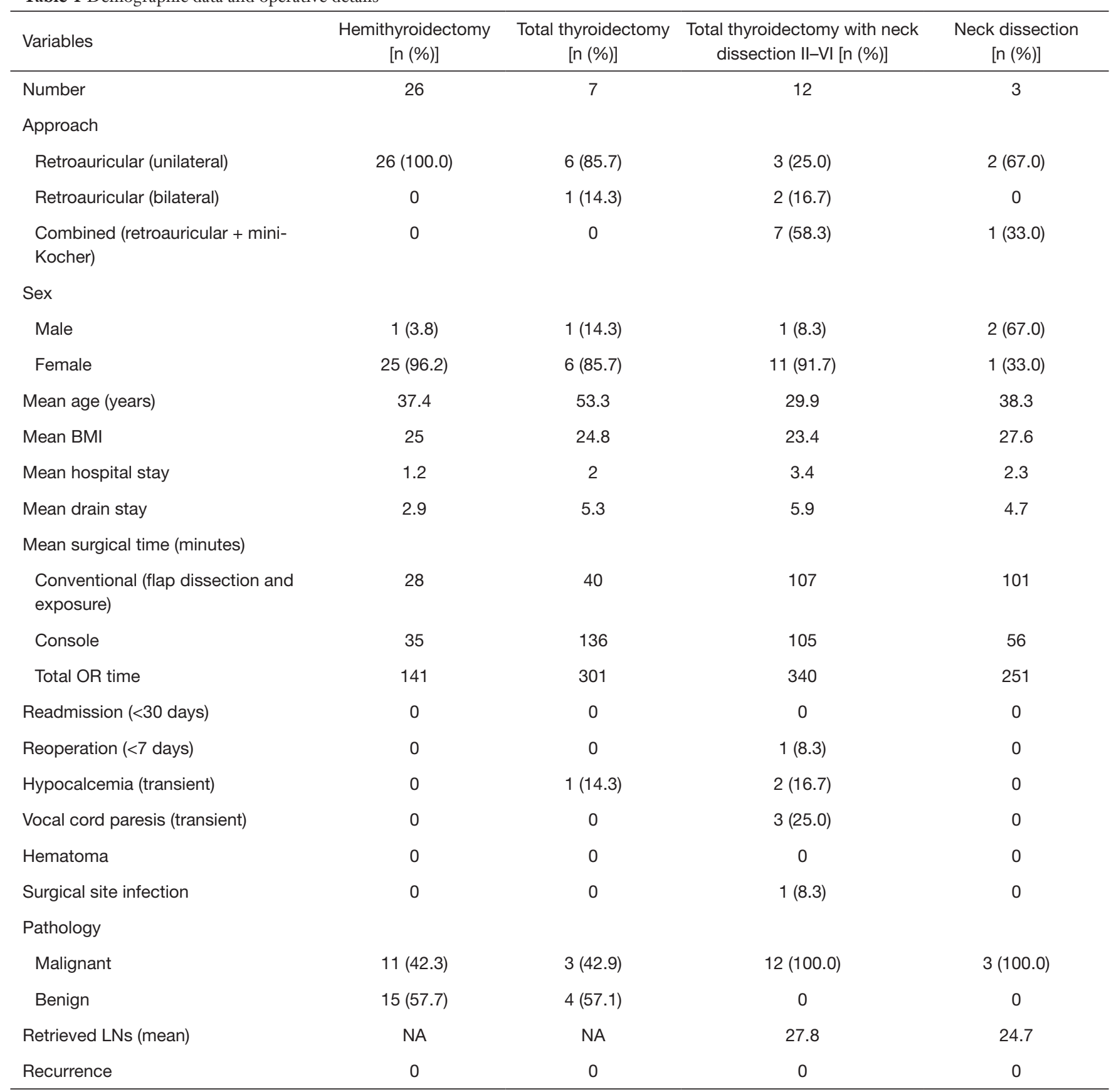

N/A, not applicable; BMI, body mass index; OR, operative room; LN, lymph node. 
evaluating outcomes of robotic thyroid surgery were published corroborating its feasibility, safety, and efficiency, with similar complication rates and oncologic results when compared with conventional and endoscopic approaches, although with longer operative times $(4,5,8-10,33,44)$.

Since 2015 we have implemented robotic and endoscopic neck surgery via the retroauricular approach in our department, becoming pioneers in these techniques in

Table 2 Comparison of outcome indicators with benchmarks

\begin{tabular}{lcc}
\hline Outcome indicators & $\begin{array}{c}\text { Robotic thyroid } \\
\text { surgery }(\mathrm{n}=48)[\mathrm{n}(\%)]\end{array}$ & $\begin{array}{c}\text { MDACC benchmarks } \\
\text { for low acuity } \\
\text { procedures }\end{array}$ \\
\hline $\begin{array}{l}\text { Length of stay } \\
\text { Readmission in }\end{array}$ & $93.7 \% \leq 3$ days & $75 \% \leq 3$ days \\
30 days & 0 & $<5 \%$ \\
$\begin{array}{l}\text { Return to OR in } \\
7 \text { days }\end{array}$ & $1(2.0)$ & $<2 \%$ \\
Mortality in 30 days & 0 & $<0.3 \%$ \\
$\begin{array}{l}\text { Blood transfusion } \\
\text { Surgical site infection } \\
\text { (30 days) }\end{array}$ & $1(2.0)$ & $75 \%<1 \mu \mathrm{n}$ \\
\end{tabular}

MDACC, MD Anderson Cancer Center.
South America (21-24). In this early experience, we have performed mainly neck dissections for different pathologies, thyroid surgeries, and submandibular gland excisions, becoming the first center outside of Asia to perform thyroid surgery combined with lateral neck dissection using the robot-assisted retroauricular approach. No significant setbacks have occurred, and now, with more than 160 procedures, safety and feasibility are no longer a question at our institution.

Robotic neck surgery using the retroauricular approach proved to be very versatile and has been used for several different neck procedures, including neck dissections, benign tumors, and salivary gland resections, in addition to thyroid surgery $(18,19,21,22,24,45-49)$. The combination of thyroid surgery and lateral neck dissection of levels IIVI using this technique can avoid the extensive neck scar of conventional surgery in patients with lateral metastasis of thyroid carcinoma. Thus, in these patients, the advantage of using a remote approach seems to be greater, and probably aesthetic and functional satisfaction is higher, as suggested by Lee et al. $(17,18)$, even in cases of bilateral retroauricular incisions.

For those experienced in robotic surgery, the intraoperative benefits from a three-dimensional (3D)enhanced high definition view and very precise dissection

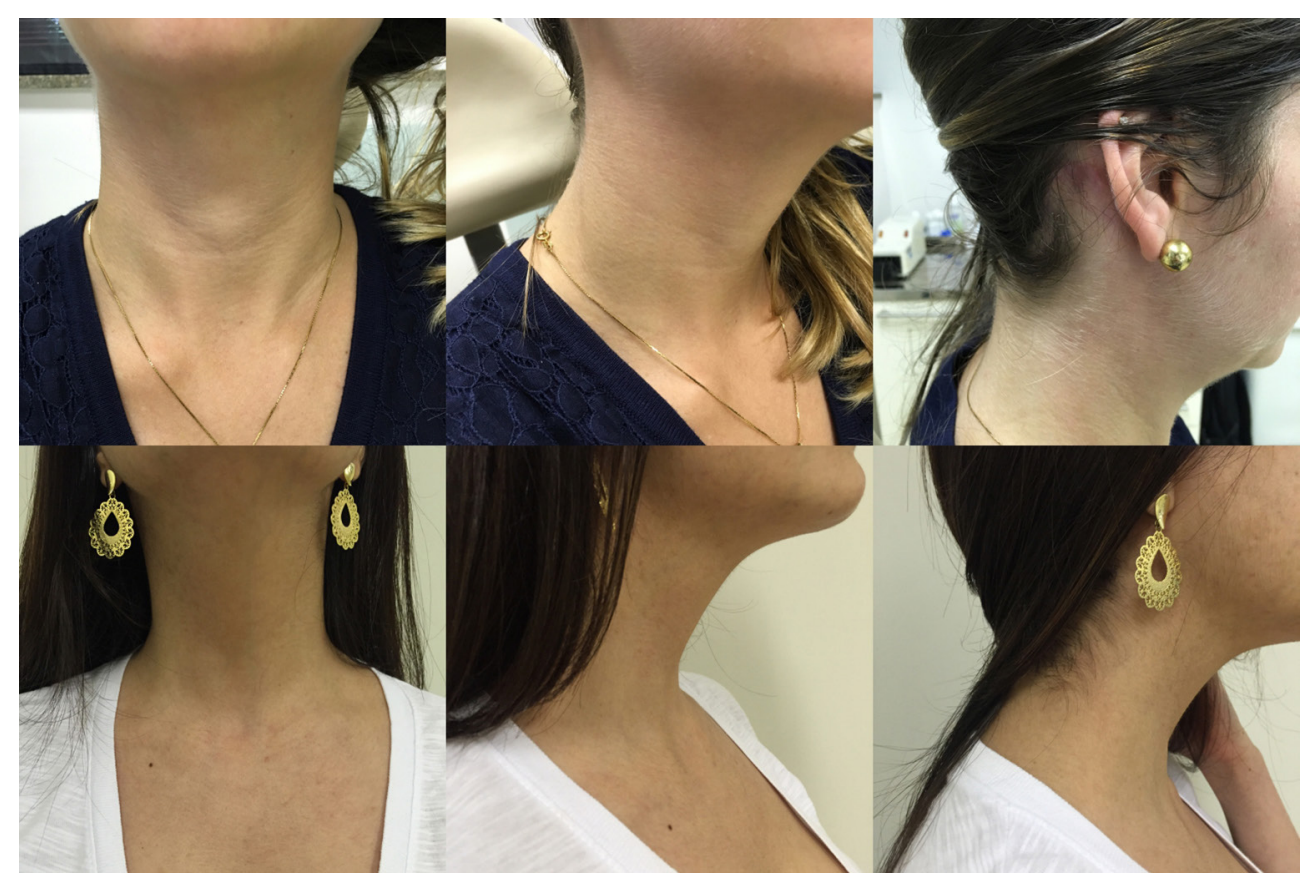

Figure 3 Neck aspect following robotic hemithyroidectomy (two cases after 3 months). 
are clear. However, this is not very often explored during debates about robotic thyroid surgery. In this initial experience, we observed no transient paresis of the recurrent laryngeal nerve during any thyroid surgery (only in cases of central compartment neck dissection), and the incidence of postoperative hypocalcemia was comparable with conventional surgery. In our opinion, the technical advantages of the robotic system could lead to less surgical trauma to the parathyroids and laryngeal nerves; however, this would be virtually impossible to prove due to the low incidence of surgical complications following thyroid surgery. So far, several publications have shown comparable rates of postoperative complications when comparing conventional to robotic thyroid surgery. In this study, we also found the complication rate to be comparable with conventional thyroid surgery according to previously published data from our group (50-54).

Quality assessment by comparing outcome indicators with established benchmarks (25-27) can be used to define the outcome of an intervention and measure an improvement in outcomes caused by a modification of a treatment or care process (55). We performed this quality assessment in this group of cases, showing that, even in the initial experience and beginning of the learning curve of robotic thyroid surgery in our department, we achieved all quality goals established for low acuity procedures.

At this time, we have not performed any objective cost analysis for a variety of reasons. First, there are several types of health insurance in Brazil, and the hospital bills usually are different according to the company and patientspecific coverage. In addition, at our hospital, we also treat private patients and patients from the public health system, causing even more heterogeneity in cost analysis. Despite that, the additional cost for robotic neck surgery is set at approximately $\$ 1,300.00$ USD at our institution and almost all patients included is this study had to pay this cost themselves, since basically none of the insurance companies would cover it. Very few studies tried to perform objective cost analysis on robotic thyroid surgery, and none were able to do a comprehensive review on this matter. We can agree that this cost is probably higher because of the use of specific drapes and instruments for the robotic system. Higher costs could also be generated from related equipment usage and prolonged operative time $(3,44,56)$.

\section{Conclusions}

In conclusion, this study brings the analysis of the first series of cases of robotic thyroid surgery from South America, showing once more the safety and feasibility of robotic thyroidectomy and also neck dissection using retro auricular incision, highlighting the versatility of this approach. Notwithstanding the already recognized technical advantages enabled by the da Vinci robotic system, the quality outcomes and complication rate seem to be comparable to the conventional approach, probably with higher cost. Therefore, we consider that robotic thyroidectomy should be an option only for selected patients that are motivated to avoid a visible neck scar, treated in high-volume centers. For the young patients who need lateral neck dissection, the retroauricular robotic approach could be more attractive for obvious reasons. More studies focused on longer oncologic follow-up and objective analysis of patient satisfaction, aesthetic, and functional results are warranted in this scenario.

\section{Acknowledgements}

None.

\section{Footnote}

Conflicts of Interest: The authors have no conflicts of interest to declare.

Ethical Statement: The study was approved by the local institutional review board (project number 1913/14) and written informed consent was obtained from all patients.

\section{References}

1. Dasgupta P, Kirby RS. The current status of robot-assisted radical prostatectomy. Asian J Androl 2009;11:90-3.

2. Goh $\mathrm{HK}, \mathrm{Ng} \mathrm{YH}$, Teo DT. Minimally invasive surgery for head and neck cancer. Lancet Oncol 2010;11:281-6.

3. Berber E, Bernet V, Fahey TJ, et al. American Thyroid Association Statement on Remote-Access Thyroid Surgery. Thyroid 2016;26:331-7.

4. Lang BH, Wong CK, Tsang JS, et al. A systematic review and meta-analysis comparing outcomes between roboticassisted thyroidectomy and non-robotic endoscopic thyroidectomy. J Surg Res 2014;191:389-98.

5. Lang BH, Wong CK, Tsang JS, et al. A systematic review and meta-analysis comparing surgically-related complications between robotic-assisted thyroidectomy and conventional open thyroidectomy. Ann Surg Oncol 
2014;21:850-61.

6. Kandil E, Saeed A, Mohamed SE, et al. Modified roboticassisted thyroidectomy: an initial experience with the retroauricular approach. Laryngoscope 2015;125:767-71.

7. Duke WS, Holsinger FC, Kandil E, et al. Remote Access Robotic Facelift Thyroidectomy: A Multi-institutional Experience. World J Surg 2017;41:116-21.

8. Jackson NR, Yao L, Tufano RP, et al. Safety of robotic thyroidectomy approaches: Meta-analysis and systematic review: Safety Comparison of Robotic Thyroidectomy: Meta-Analysis. Head Neck 2014;36:137-43.

9. Shen H, Shan C, Qiu M. Systematic review and metaanalysis of transaxillary robotic thyroidectomy versus open thyroidectomy. Surg Laparosc Endosc Percutan Tech 2014;24:199-206.

10. Son SK, Kim JH, Bae JS, et al. Surgical safety and oncologic effectiveness in robotic versus conventional open thyroidectomy in thyroid cancer: a systematic review and meta-analysis. Ann Surg Oncol 2015;22:3022-32.

11. McLeod IK, Melder PC. Da Vinci robot-assisted excision of a vallecular cyst: a case report. Ear Nose Throat J 2005;84:170-2.

12. O'Malley BW, Weinstein GS, Snyder W, et al. Transoral robotic surgery (TORS) for base of tongue neoplasms. Laryngoscope 2006;116:1465-72.

13. Weinstein GS, O'Malley BW, Magnuson JS, et al. Transoral robotic surgery: A multicenter study to assess feasibility, safety, and surgical margins. Laryngoscope 2012;122:1701-7.

14. de Almeida JR, Li R, Magnuson JS, et al. Oncologic Outcomes After Transoral Robotic Surgery: A Multiinstitutional Study. JAMA Otolaryngol Head Neck Surg 2015;141:1043-51.

15. Wang MB, Liu IY, Gornbein JA, et al. HPV-Positive Oropharyngeal Carcinoma: A Systematic Review of Treatment and Prognosis. Otolaryngol Head Neck Surg 2015;153:758-69.

16. Terris DJ, Singer MC, Seybt MW. Robotic facelift thyroidectomy: II. Clinical feasibility and safety: Robotic Facelift Thyroidectomy. Laryngoscope 2011;121:1636-41.

17. Lee J, Kwon IS, Bae EH, et al. Comparative Analysis of Oncological Outcomes and Quality of Life After Robotic versus Conventional Open Thyroidectomy With Modified Radical Neck Dissection in Patients With Papillary Thyroid Carcinoma and Lateral Neck Node Metastases. J Clin Endocrinol Metab 2013;98:2701-8.

18. Lee J, Chung WY. Robotic thyroidectomy and neck dissection: past, present, and future. Cancer J 2013;19:151-61.

19. Tae K, Ji YB, Song CM, et al. Robotic Selective Neck Dissection by a Postauricular Facelift Approach: Comparison with Conventional Neck Dissection. Otolaryngol Head Neck Surg 2014;150:394-400.

20. Byeon HK, Holsinger FC, Tufano RP, et al. Robotic total thyroidectomy with modified radical neck dissection via unilateral retroauricular approach. Ann Surg Oncol 2014;21:3872-5.

21. Lira RB, Chulam T, Koh Y, et al. Retroauricular Endoscope-Assisted Approach to the Neck: Early Experience in Latin America. Int Arch Otorhinolaryngol 2016;20:138-44.

22. Chulam TC, Lira RB, Kowalski LP. Robotic-assisted modified retroauricular cervical approach: initial experience in Latin America. Rev Col Bras Cir 2016;43:289-91.

23. Lira RB, Chulam TC, Kowalski LP. Safe implementation of retroauricular robotic and endoscopic neck surgery in South America. Gland Surg 2017;6:258-66.

24. Lira RB, Chulam TC, de Carvalho GB, et al. Retroauricular endoscopic and robotic versus conventional neck dissection for oral cancer. J Robot Surg 2018;12:117-29.

25. Lira RB, de Carvalho AY, de Carvalho GB, et al. Quality assessment in head and neck oncologic surgery in a Brazilian cancer center compared with MD Anderson Cancer Center benchmarks. Head Neck 2016;38:1002-7.

26. Weber RS, Lewis CM, Eastman SD, et al. Quality and performance indicators in an academic department of head and neck surgery. Arch Otolaryngol Head Neck Surg 2010;136:1212-8.

27. Shellenberger TD, Madero-Visbal R, Weber RS. Quality indicators in head and neck operations: a comparison with published benchmarks. Arch Otolaryngol Head Neck Surg 2011;137:1086-93.

28. Mohamed SE, Noureldine SI, Kandil E. Alternate incision-site thyroidectomy: Curr Opin Oncol 2014;26:22-30.

29. Stack BC, Ferris RL, Goldenberg D, et al. American Thyroid Association Consensus Review and Statement Regarding the Anatomy, Terminology, and Rationale for Lateral Neck Dissection in Differentiated Thyroid Cancer. Thyroid 2012;22:501-8.

30. Anuwong A, Ketwong K, Jitpratoom P, et al. Safety and Outcomes of the Transoral Endoscopic Thyroidectomy 
Vestibular Approach. JAMA Surg 2018;153:21-7.

31. Tae K, Ji YB, Jeong JH, et al. Robotic thyroidectomy by a gasless unilateral axillo-breast or axillary approach: our early experiences. Surg Endosc 2011;25:221-8.

32. Lee J, Nah KY, Kim RM, et al. Differences in postoperative outcomes, function, and cosmesis: open versus robotic thyroidectomy. Surg Endosc 2010;24:3186-94.

33. Kandil E, Hammad AY, Walvekar RR, et al. Robotic thyroidectomy versus nonrobotic approaches: a metaanalysis examining surgical outcomes. Surg Innov 2016;23:317-25.

34. Chung EJ, Park MW, Cho JG, et al. A prospective 1-year comparative study of endoscopic thyroidectomy via a retroauricular approach versus conventional open thyroidectomy at a single institution. Ann Surg Oncol 2015;22:3014-21.

35. Lee DY, Oh DJ, Kang KR, et al. Comparison of Learning Curves for Retroauricular and Transaxillary Endoscopic Hemithyroidectomy. Ann Surg Oncol 2016;23:4023-8.

36. Lee DY, Lee KJ, Han WG, et al. Comparison of transaxillary approach, retroauricular approach, and conventional open hemithyroidectomy: A prospective study at single institution. Surgery 2016;159:524-31.

37. Byeon HK, Kim DH, Chang JW, et al. Comprehensive application of robotic retroauricular thyroidectomy: The evolution of robotic thyroidectomy. Laryngoscope 2016;126:1952-7.

38. Park JO, Kim SY, Chun BJ, et al. Endoscope-assisted facelift thyroid surgery: an initial experience using a new endoscopic technique. Surg Endosc 2015;29:1469-75.

39. Byeon HK, Holsinger FC, Tufano RP, et al. Endoscopic retroauricular thyroidectomy: preliminary results. Surg Endosc 2016;30:355-65.

40. Lee DY, Baek SK, Jung KY. Endoscopic thyroidectomy: retroauricular approach. Gland Surg 2016;5:327-35.

41. Ban MJ, Chang JW, Kim WS, et al. Minimal Endoscopeassisted Thyroidectomy Through a Retroauricular Approach: An Evolving Solo Surgery Technique. Surg Laparosc Endosc Percutan Tech 2016;26:e109-12.

42. Alabbas H, Bu Ali D, Kandil E. Robotic retroauricular thyroid surgery. Gland Surg 2016;5:603-6.

43. Alshehri M, Mohamed HE, Moulthrop T, et al. Robotic thyroidectomy and parathyroidectomy: An initial experience with retroauricular approach. Head Neck 2017;39:1568-72.
44. Sun GH, Peress L, Pynnonen MA. Systematic review and meta-analysis of robotic vs conventional thyroidectomy approaches for thyroid disease. Otolaryngol--Head Neck Surg Off J Am Acad Otolaryngol Head Neck Surg 2014;150:520-32.

45. Byeon HK, Holsinger FC, Kim DH, et al. Feasibility of robot-assisted neck dissection followed by transoral robotic surgery. Br J Oral Maxillofac Surg 2015;53:68-73.

46. Greer Albergotti W, Kenneth Byrd J, De Almeida JR, et al. Robot-assisted level II-IV neck dissection through a modified facelift incision: initial North American experience: Robot-assisted neck dissection. Int J Med Robot 2014;10:391-6.

47. Park YM, Holsinger FC, Kim WS, et al. Robot-Assisted Selective Neck Dissection of Levels II to V via a Modified Facelift or Retroauricular Approach. Otolaryngol Head Neck Surg 2013;148:778-85.

48. Lee HS, Kim WS, Hong HJ, et al. Robot-assisted Supraomohyoid Neck Dissection via a Modified Face-lift or Retroauricular Approach in Early-stage cN0 Squamous Cell Carcinoma of the Oral Cavity: A Comparative Study with Conventional Technique. Ann Surg Oncol 2012;19:3871-8.

49. Terris DJ, Singer MC. Robotic facelift thyroidectomy: Facilitating remote access surgery. Head Neck 2012;34:746-7.

50. Lira RB, Carvalho GB, Gonçalves Filho J, et al. Evolution in the profile of thyroid cancer cases treated in an oncology reference service: what changed in the last 20 years. Rev Col Bras Cir 2014;41:320-4

51. Ywata de Carvalho A, Chulam TC, Kowalski LP. Longterm Results of Observation vs Prophylactic Selective Level VI Neck Dissection for Papillary Thyroid Carcinoma at a Cancer Center. JAMA Otolaryngol Head Neck Surg 2015;141:599-606.

52. Filho JG, Kowalski LP. Postoperative complications of thyroidectomy for differentiated thyroid carcinoma. Am J Otolaryngol 2004;25:225-30.

53. Gonçalves Filho J, Kowalski LP. Surgical complications after thyroid surgery performed in a cancer hospital. Otolaryngol Head Neck Surg 2005;132:490-4.

54. Netto Ide P, Vartanian JG, Ferraz PR, et al. Vocal fold immobility after thyroidectomy with intraoperative recurrent laryngeal nerve monitoring. Sao Paulo Med J 2007;125:186-90

55. Vila PM, Schneider JS, Piccirillo JF, et al. Understanding Quality Measures in Otolaryngology-Head and 
Neck Surgery. JAMA Otolaryngol Head Neck Surg 2016;142:86-90.

56. Cabot JC, Lee CR, Brunaud L, et al. Robotic and

Cite this article as: Lira RB, Chulam TC, Kowalski LP. Variations and results of retroauricular robotic thyroid surgery associated or not with neck dissection. Gland Surg 2018;7(Suppl 1):S42-S52. doi: 10.21037/gs.2018.03.04 endoscopic transaxillary thyroidectomies may be cost prohibitive when compared to standard cervical thyroidectomy: a cost analysis. Surgery 2012;152:1016-24. 